\title{
The course-of-action research program : historical and conceptual landmarks
}

Le programme de recherche "cours d'action ": repères historiques et conceptuels

\section{Germain Poizat and Julia San Martin}

\section{(2) OpenEdition}

\section{Journals}

Electronic version

URL: https://journals.openedition.org/activites/6434

DOI: 10.4000 /activites. 6434

ISSN: $1765-2723$

Publisher

ARPACT - Association Recherches et Pratiques sur les ACTivités

Electronic reference

Germain Poizat and Julia San Martin, "The course-of-action research program : historical and conceptual landmarks", Activités [Online], 17-2 | 2020, Online since 15 October 2020, connection on 25 August 2021. URL: http://journals.openedition.org/activites/6434 ; DOI: https://doi.org/10.4000/ activites.6434

This text was automatically generated on 25 August 2021

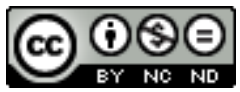

Activités est mis à disposition selon les termes de la licence Creative Commons Attribution - Pas d'Utilisation Commerciale - Pas de Modification 4.0 International. 


\title{
The course-of-action research program : historical and conceptual landmarks
}

\author{
Le programme de recherche " cours d'action »: repères historiques et \\ conceptuels
}

Germain Poizat and Julia San Martin

\section{This is not an introduction}

1 This article introduces the course-of-action program and is thus not necessarily an introduction to this special issue. It offers a synoptic view of the program, providing a minimal framework for reading and comparing with other programs or theories and precluding the need for excessively long introductory explanations in the other articles of this issue. The hypotheses, methods, and descriptive categories for the course-ofaction program are presented, as well as the recent advances of those who have contributed to its development or who conduct research within its framework. We first briefly present its history and how it was extended to various empirical and sociotechnical fields and then review (1) its ontological and epistemological foundations ; 2) the theoretical objects, which are scientific reductions of activity that ensure empirically ascertainable studies ("holistic" and ideally "non-reductionist") ; (3) the observatory and methodological workbench; (4) the semiological framework and the various ways it can be implemented; 5) the design approach and its main components ; and (6) the extensions of the program into new areas in the most recent research. 


\section{The course-of-action research program : a brief overview of its history}

2 It should first be noted that this brief historical overview is in no way exhaustive : (1) it reflects the authors' points of view regarding various periods in the past and does not take into account the points of view of the actors themselves, ${ }^{1}$ and (2) it is "situated," which means that it is influenced by the collective publication project presented in this issue. Yet, this brief overview will help readers to better understand and situate what has usually been called the course-of-action program in ergonomics and more broadly in activity studies. A more detailed analysis of the academic, historical, political, and social contexts is surely warranted, even essential, as would be micro-historical studies on French-language ergonomics. Yet embarking on such detailed historical research would be a sizeable undertaking. Here, we provide only some of the highlights and milestones within the scientific and historical context.

\subsection{An evolution in ergonomics, cognitive anthropology and enaction}

3 The course-of-action research program was initially developed in the field of ergonomics in the 1980s. The very notion of the "course of action"2 appeared for the first time in a report published in 1987 (Pinsky \& Theureau, 1987) following a series of studies started in 1977 on cognitive activity and action in work environments (Pinsky \& Theureau, 1982). The first attempts to systematize the research program appeared a few years later through the works of Theureau (1992), Pinsky (1992) and Theureau and Jeffroy (1994). At that time, the only empirical and sociotechnical fields taken into account were work settings (and more precisely ordinary work settings) with a view to the ergonomic design of computerized and automated situations. One study had been conducted on learning-development with the aim of improving on-the-job training (Vion, 1993) but was not presented by Theureau and Jeffroy (1994).

4 The first course-of-action studies appeared at a time when ergonomics was being restructured in France under the leadership of Wisner, Montmollin, Cazamian, Leplat, Teiger, and Bouisset, to name but a few. Research in ergonomics, which was readily accepted as "French-speaking ergonomics," was torn between two orientations. First, experimental (laboratory) research was based on a strictly positivist idea, in close association with established scientific disciplines. This research was being conducted in a period characterized by transformations in the relationship between physical and mental work (although the distinction was already the subject of debate and strong controversy), the development of automated systems and human-machine interactions, and the growing hegemony of cognitive psychology, with the development of an ergonomic cognitive psychology or cognitive ergonomics. Yet, other research showed a different orientation by pursuing more practically and socially engaged studies, thus remaining at a greater (short-term) distance from academic norms and expectations, and by also maintaining more distant relations with the well-known scientific disciplines (although many were based on occupational physiology). Their authors insisted not only on the importance of the practical/social issues associated with ergonomics, but also on the possibility of knowledge production within the framework of ergonomic interventions. It is in this context that a pioneering and exemplary study 
was carried out at the Thomson Angers (French company), by Laville, Teiger and Duraffourg (1972). Described as "global research in a real situation" (Tort, 1974) and more recently as the "first field research" in francophone ergonomics (Teiger, Barbaroux, David, Duraffourg, Galisson, Laville, \& Thareaut, 2006), this study radically distinguished itself from the experimental studies in psychology and occupational physiology. Researchers (1) left the laboratory and adapted their tools and methods to real work situations, (2) attempted to capture work activity in a holistic manner, and (3) gave real "voice" to workers on their work activity and its conditions. ${ }^{3}$ In a newsletter of the French Speaking Ergonomics Society (SELF) in tribute to Antoine Laville, Jeffroy (2003) stated that this study "laid the foundations for an original approach to ergonomics that combines physiology, psychology and work analysis; observation in situation and laboratory experimentation; research and intervention ... Most of the questions and research issues opened up by this research are still relevant, which shows the fruitfulness of the hypotheses." To a certain extent, course-of-action studies conducted in work settings have always been thought of as extensions, developments, and refinements of this outof-the-laboratory research in the direction of empirical "field" research that (1) is attentive to work situations in all their fullness and (2) gives importance to actors' points of view in the analyses of their activities and the conception of their situations. One of the limitations of the Thomson Angers study, however, was the status accorded ontologically and epistemologically to the "discourse" or "voice" of the operators on their work. This limitation was considered a posteriori to be quite real by Teiger et al. (2006) and has since been overcome, according to the authors themselves, within the framework of the course-of-action program with Theureau and Pinsky's development of the self-confrontation (Pinsky \& Theureau, 1982, 1987; Theureau \& Pinsky, 1983). This pioneering research in Thomson Angers was thus a major contribution because it gave an important place to the actors' points of view and opened up the possibility of using verbalizations as relevant and reliable empirical data (Pinsky \& Theureau, 1982).

5 As noted, the course-of-action program emerged in an environment characterized by the predominance of well-known scientific disciplines, notably psychology and physiology, with which ergonomics had a sometimes tumultuous and ambivalent relation. ${ }^{4}$ The early course-of-action studies were concerned only with ill-defined empirical and sociotechnical-organizational problems from the perspective of these disciplines. They thus showed themselves very early on to be "un-disciplined" by carefully keeping a distance from the scientific disciplines, in part through the idea of structuring research into a scientific research program. Theureau (2015a), like others, indeed considers the scientific disciplines as contingent historical constructions, granting them only a two-part secondary role in the production of knowledge : (1) as a "conservatory," in that they organize and teach provisional knowledge, and (2) as momentary resources to be drawn on for any research problem for which interdisciplinarity is recommended before then being resolved through a local and situated transdisciplinarity. The structuring of course-of-action studies into a scientific research program (Lakatos, 1994) made the pursuit of scientific issues clearly explicit, while allowing for a local and situated transdisciplinarity partly freed from disciplines.

6 Finally, the researchers within the course-of-action program insisted, again like others at the time (Daniellou, Pavard, Wisner, and de Montmollin, to name but a few), on their participation in the design and transformation of work situations in a context where studies (in I/O psychology) mainly devolved these transformations to others (management, methods engineers, union negotiators). This was reflected in the course- 
of-action research program by a constant and early preoccupation with design issues and the development of "situation engineering," notably under the leadership of Leonardo Pinsky (Pinsky, 1990, 1992 ; Pinsky \& Pavard, 1984 ; Theureau \& Pinsky, 1984).

7 Very early on, Theureau and Pinsky established and maintained many enriching exchanges with North American cognitive anthropologists, even explicitly stating their connection to this stream. ${ }^{5}$ In search of an alternative to the cognitivist paradigm and the "upper psychologization" of the analysis of work and activity, course-of-action researchers turned to cognitive anthropology in 1988 at a moment of intense scientific debate between the supporters of situated action/cognition and those of human problem-solving (Clancey, 1993 ; Suchman, 1993 ; Vera \& Simon, 1993). After numerous discussions between 1985 and 1988 with Norman, Hutchins, Cicourel, Goodwin, Suchman, Lave, Scribner and Cole, it became increasingly evident that course-of-action research was closely aligned with those North American studies that (1) proposed convergent, alternative or complementary visions of action and cognition, and (2) claimed to be doing cognitive anthropology (Dougherty, 1985) - or cognitive ethnography - which was thought of as an extension of the theoretical and methodological achievements of North American (Malinowskian) cultural anthropology through the study of cognitive processes. The interest of North American cognitive anthropology was that it combined field research, rigorous data collection and modeling and, in some cases, practical aims to improve the situations of actors through the design of artifactual, organizational, and cultural systems. At that time, studies in cognitive anthropology were clustered around a common project that coincided with that of the course-of-action program: "the empirical and theoretical characterization of situationally specific cognitive activity" (Lave, 1988, p. 3) and taking "the situated character of activity (including cognition) as given [...] to explore its dimension" (Lave, 1988, p. 93). Pavard also closely followed these studies in cognitive anthropology, and they had an influence on the analyses and models of situated cooperative activities that he subsequently proposed in collaboration with other researchers. In a second phase, Wisner learned about the North American work in cognitive anthropology through the intermediary of Pavard and Theureau and fully integrated it into an anthropotechnological project alongside a French-language cultural anthropology (Wisner, 1995). ${ }^{6}$

8 The decisive encounter between the course-of-action program and the enaction paradigm took place more or less at the same time as the encounter with North American cognitive anthropology via the meeting of Winograd and Pinsky during Pinsky's trip to the United States in 1986. Winograd was preparing to publish a book with Flores on developments in design principles based on the enaction paradigm (Winograd \& Flores, 1986) - principles that they had concretized in a project to design software in support of cooperation. These authors thus helped guide course-of-action studies toward the work of Varela and then tried to extend them toward an enactive approach to human activity and design. In 1987, the enaction paradigm was mentioned (only) in the conclusion of a report from the Laboratory of the National Conservatory of Arts and Crafts (CNAM) (Pinsky \& Theureau, 1987) as a point of support for discussions. Yet, this paradigm very quickly (1992) imposed itself and today is the basis for the ontological and epistemological presuppositions of the empirical and technological course-of-action research programs (Pinsky 1992 ; Theureau, 1992 ; Theureau \& Jeffroy, 1994). Recently, the enaction paradigm has also been deployed within the framework of the distributed cognition program, which has brought these two research programs 
closer together, although they had always maintained a fruitful dialogue (see Theureau in this issue).

\subsection{Extension and development of the course-of-action program in areas other than work analysis in ergonomics}

9 As it has developed, the course-of-action program has undergone several systematizations (in particular with regard to the semiological theoretical framework) and disseminations. ${ }^{7}$ During these different waves of systematization-dissemination, the program has become increasingly concretized ${ }^{8}$ and conceptually/empirically consistent, although at the risk of making it somewhat hermetic, in part due to the sophistication of its system of descriptive categories.

In addition to these successive systematizations and disseminations, it is important to underline the extension and development of the research program in areas other than ergonomics. The studies carried out up to 1994 and forming the empirical anchor of the "elementary method" (Theureau, 1992, 2004 ; Theureau \& Jeffroy, 1994) dealt almost exclusively with work (in ordinary situations) in industry, services and agriculture, and they aimed to contribute to the "engineering of work situations" in all their dimensions (workspace, software and computer applications, automation, technical devices, organization, procedures, and training).

11 Since then, this empirical research on work activities has continued in many different directions. ${ }^{9}$ Examples include the studies on the individual and collective activity of operating/monitoring a nuclear reactor in an incident-accident situation using computerized procedures and/or by adjusting written procedures (Theureau, Filippi, Saliou, \& Vermersch, 2001), the collective construction of traffic regulation in a RER train network control room (Theureau \& Filippi, 2000); the collective activity of printing operators for safety and prevention (Dequaire-Falconnet, 2001), user activity and the design of human-machine interactions (Haradji \& Faveaux, 2006), passenger activity at the Gare du Nord train station for planning and designing public spaces and passenger information systems (Theureau, 1997a), driving activity for the design of assistance systems (Haué, Le Bellu, \& Barbier, 2020), domestic activity for the design of products and services for energy management (Haué, 2004; Guibourdenche, Vacherand-Revel, Fréjus, \& Haradji, 2015), and the activity in service relationships for the design of technical and organizational assistance (Motté \& Haradji, 2010).

12 At the same time, course-of-action research continued to develop and has seen a revival in the field of artistic, cultural and mediation practices; the field of sports sciences and sports interventions; and the field of educational and training sciences. We list below some of the studies that reflect the abundance of research that has flourished in these three areas.

13 In the artistic and cultural field, research has been carried out on the activity of composition and musical creation in connection with the design of enriched musical listening situations (Goldszmidt \& Theureau, 2010), the conductor's activity during rehearsal (Donin \& Theureau, 2007), the collective activity of the joint conception of a work and a computer system for string quartet (Donin, Goldszmidt, \& Theureau, 2009), and even visitor activity in museums in connection with the design of mediation devices (whether or not including digital technologies) (Schmitt, 2015 ; see Gobbato, Blondeau, Thébault, \& Schmitt in this issue). 

athletes in competition (decision-making, building and mobilizing knowledge, emotional dynamics) (Rochat, Gesbert, Seifert \& Hauw, 2018 ; Sève, Ria, Poizat, Saury, \& Durand, 2007 ; Sève, Saury, Theureau \& Durand, 2002), the activity of coaches and the coach-athlete relationship (d'Arripe-Longueville, Saury, Fournier, \& Durand, 2001), and cooperation and coordination in sports (Bourbousson, Poizat, Saury, \& Sève , 2011), all articulated around the design of sports performance aids (Sève, Poizat, Saury, \& Durand, 2006). We also note studies on the activity of athletes in connection with the use of doping products (Hauw \& Mohamed, 2015) with a view to developing anti-doping services and preventive actions, as well as research on sports activity or instrumented training situations with a view to designing sports equipment (Rochat, Hauw, \& Seifert, 2019). activity of teachers in the classroom and teacher-student-artifact interactions (Adé, Veyrunes, \& Poizat, 2009; Flavier, Bertone, Hauw, \& Durand, 2002; Veyrunes \& San Martin, 2016; Vors \& Gal-Petitfaux, 2008), the learning activity of students (Dieumegard, 2011; Évin, Sève, \& Saury, 2015), collective activity in homework practices (Bonasio \& Veyrunes, 2016), the activity of preservice teachers in training situations and particularly in video training situations designed from the results of previous empirical studies (Chaliès et al., 2004 ; Flandin \& Ria, 2014 ; Leblanc et al., 2008; Ria \& Leblanc, 2011), and the development of collective and organizational learning dedicated to the improvement of student learning (Bonasio, Fondeville, \& Veyrunes, 2015). Several syntheses have been produced, addressing the empirical aspects or the design of training programs for teachers or teacher trainers (Durand \& Veyrunes, 2005 ; Durand, Saury, \& Veyrunes, 2005 ; Saury, Adé, Gal-Petitfaux, Huet, Sève, \& Trohel, 2013 ; San Martin, Veyrunes, Martinic, \& Ria, 2017). Much research has also been carried out in the field of adult education and vocational training. These studies have focused on the activity of educational and career guidance counselors during validation procedures (Salini \& Durand, 2012), the activity of occupational safety inspectors in the building sector (De Moraes-Piers \& Durand, 2011), the activity of nurse-anesthetists during simulation-training situations (Horcik, Savoldelli, Poizat, \& Durand, 2014), the activity of radiographers at work and during training situations (Schot, Flandin, Goudeaux, Seferdjeli \& Poizat, 2019), the constraints and effects of digitization on service activities (Salini, Jaramillo, Goudeaux, \& Poizat 2018), the activity of chronically ill people in art-mediated educational practices (Nello, 2017; Salini \& Durand, 2020), the activity of construction professionals (Antipoff \& Lima, 2017), and the activity of participants (with no or little professional experience) during crisis exercises and simulations (Flandin, Poizat, \& Durand, 2018). Another study focused on the analysis of the activity of ergonomics consultants and the training of ergonomists (Viau-Guay, 2009). These studies on adult education and vocational training form part of the convergences and complementarities with the work carried out on training in ergonomics (Lacomblez, Bellemare, Chatigny, Delgoulet, Re, Trudel, \& Vasconcelos, 2007 ; Lacomblez \& Vasconcelos, 2009 ; Teiger \& Lacomblez, 2013).

Studies have been conducted on the activity of managers in manufacturing (Dieumegard, Saury, \& Durand, 2004), the activity of a manager in the publishing industry (Durand, 2013), and the collective activity in service relationships in the commercial field (Poret, Folcher, Motté, \& Haradji, 2016). Yet despite these studies and 
various theoretical contributions (Theureau, 2000), overall little research has been conducted in management and on the practices of managers. This is surprising, as research in relation to management structure, organizational design, governance, and logistics should go without saying. It has in any case been called for in various fields, particularly in safety management or in studies on adult and workplace learning.

\section{Epistemological and ontological foundations of the course-of-action research program}

17 Studies in the course-of-action program pursue two types of aims that have more or less priority, are more or less synchronous or asynchronous, and are materialized at different levels - from the broadest to the most specific: aims that are epistemic, concerning the production of scientific knowledge, comprehension, or intelligibility; and aims that are transformative, concerning intervention, design, or action. These aims cannot be reduced to a classic and applicationist articulation between theory and practices but are intrinsically, inherently, and substantially linked. In the course-ofaction program, this articulation is understood as a constructed relationship, conceptualized as organic, between two coordinated and mutually constraining/ enabling programs : an empirical research program (giving primacy to the aim of producing scientific knowledge about the world) and a technological research program (giving primacy to the transformation of the world). Also, three scientific criteria are defined within the framework of the empirical course-of-action program (Theureau, 2006): the literalization of the empirical, refutability, and the relationship with technique. This last criterion, borrowed from Milner (1995) and based on the work of Koyré (1971), is fundamental insofar as it implies a positioning of research in relation to technique and technology (Pinsky, 1992) on the assumption that this organic relationship between science and technology is not a criterion of contemporary science alone, but of science itself. The affirmation of a structuring into a technological research program and the affirmation of the organic relationship with one or more empirical research programs has made it possible to open up a non-applicationist relationship between research and design.

\subsection{The epistemological ideal of structuring into empirical and technological research programs}

18 The research ideal of structuration pursued by course-of-action studies is the methodology of scientific research programs (Lakatos, 1994). This "programmatic" ideal offers various advantages, notably helping to avoid the risk of drifting or wandering in a succession of "institutional" or "industrial" projects ; explicitly defining the modalities of research validation, extension and development; avoiding disciplinary downturn and promoting transdisciplinary; more clearly distinguishing the various forms of engineering, from the most applicative to the most organically and recursively articulated with empirical research; and combining creative individual research and collective research in a fruitful way. This epistemological ideal is a real aid to the activity of researchers in the daily conduct of their surveys/studies.

19 Course-of-action studies pursue this programmatic structuring on the assumption that it is also a relevant unit for the evaluation of research - empirical or technological. It 
also makes possible the coexistence of a plurality of programs that are, in a given situation, partly similar, partly complementary and partly competitive. By doing so, "research areas" are created. Structuring a research program and being able to explain it in detail facilitates not only the engagement in debate and controversies, but also the connections and mutual fertilization with other research programs (Bertone \& Chaliès, 2015). The article by Theureau (in this issue) in particular explores and discusses the complementarities, enrichments and past, current, and future debates between the course-of-action research program and the distributed cognition research program developed by Hutchins $(1995,2010) .{ }^{10}$ Bationo-Tillon, Poret and Folcher's article (in this issue) proposes combining an instrumental approach and the course-of-action research program in the service of understanding and supporting organizational genesis from a transitional perspective.

Regarding the "transformative" component, we have seen that structuring into a technological research program makes it possible to imagine a non-applicationist relationship between scientific/academic research and design/intervention/action and provides explicit foundations for design practices. This requires adopting the same constraints as for empirical research, namely, specifying the constituent elements of the program and the relationships that bind them, and maintaining an organic relationship with one or more empirical programs. A technological research program precisely defines : (1) a hard core of postulates and general and non-trivial empirical hypotheses that (2) govern the design and underpin non-trivial (and refutable) propositions regarding sought-after technical-cultural-organizational and educational efficiency; (3) provide the basis for design choices, objects and criteria; and (4) document the construction of an observatory, a workbench ${ }^{11}$ and technical-culturalorganizational and educational tests of efficiency. The criteria of validity for a technological research program thus become technical-cultural-organizational and educational efficiency, the organic relationship with empirical research, and the fit with explicit values (Theureau, 2006).

21 In each of the empirical and design fields, specific or local - empirical and technological - programs have tended to develop while still maintaining specific relationships with the empirical and technological research traditions of these different fields - see, for example, Haradji \& Faveaux (2006) in ergonomics and Durand (2008) in educational sciences - and while taking into account current empirical and technological issues and advances (such as, for example, advances in the field of simulation). Two generic programs can thus be distinguished - one empirical and one technological - which constrain and empower specific, local empirical and technological programs, each having its own dynamics of existence but each in return enriching the two generic programs.

\subsection{The fundamental assumptions of the course-of-action research program}

The first originality of the course-of-action program concerns the definition of the hard core of fundamental assumptions. These are the fundamental hypotheses that represent the themata that guide research and are protected from any refutation by a negative heuristic : researchers do not seek to refute them although they leave others free to do so. This makes it possible to maintain the coherence of the program for a 
given time and to "protect" it for the time it takes to produce empirical (and/or technological) research and show its fruitfulness. The dynamics of the program are thus based on a double heuristic : one negative that concerns the protection of the hard core, the other positive that tries to refute auxiliary hypotheses.

These fundamental assumptions correspond to the conjunction of two ontological hypotheses: (1) the hypothesis of enaction, and (2) the hypothesis of pre-reflexive consciousness (or experience). The program is also based on an analytical hypothesis the hypothesis of the activity-sign, resulting from the notion of Peirce's thought-sign and an "explanatory" hypothesis - the hypothesis of the constraints and effects of human activity in the bodies of the actors, their situations and their cultures.

The hypothesis of enaction. According to this hypothesis, the cognitive activity or cognition (in the broadest sense) of actors consists of a dynamic structural coupling with the environment, or even of a succession or flow of interactions between them and their environment. These interactions are in-formative in the sense that the internal organization of the actors circumscribes at each moment what in the environment is likely to disturb them and mold/steer (but not command) the response that can be brought to this disturbance, the response being one that transforms the actors' internal organization, as well as the situation and potentially the environment. Defining in-formative interactions consists of taking into account the observation that an individual's organization orients or circumscribes moment-by-moment (1) what in the environment is likely to disturb him or her and (2) the dynamic of meaningmaking.

These notions apply to a single actor or to a collective of actors, the latter on condition that the in-formative interactions with the environment involve the participating actors. The activity of an actor is never purely individual, but individual-social, just as the activity of a collective of actors is never purely collective, but social-individual. A collective is constantly challenged and rebuilt by the individual activities of the actors who make it up : they are autonomous while being constrained by the collective. The hypothesis of enaction makes it possible to break here with both methodological individualism, according to which human activity is based on the individual characteristics of the actors, and methodological collectivism, according to which human activity is based monopolistically on the characteristics of collectives or the interactions between the members of collectives. In the course-of-action program, an understanding of social-individual activity cannot be achieved without an understanding of individual-social activity, just as an understanding of the individualsocial activity of an individual actor cannot be achieved without taking into account the activity of the other actors in an environment that is only partially shared.

The hypothesis of pre-reflexive consciousness (or experience). The hypothesis of prereflexive consciousness emerged from Sartre's philosophical work and its transformation, especially in conjunction with the hypothesis of enaction. According to this hypothesis, (1) at any instant and under favorable conditions, an actor can show, mime, simulate, tell and comment on his or her activity to an observer-interlocutor, and (2) these acts of showing, miming, simulating, telling and commenting constitute the surface effect (or an outcrop) of the in-formative interactions between this actor and the environment and their complex temporal organization. When this possibility of showing, miming, simulating, telling and commenting on one's activity is actualized in 
one way or another, we speak of the actualization of pre-reflexive consciousness or immediate experience.

The hypothesis of pre-reflexive consciousness is central to the course-of-action program and fundamentally implies a relationship to others (Sartre \& Lévy, 1991). This characteristic is one of the prerequisites for the very existence of collective activity: for collective activity to be possible, each individual must be capable of a certain understanding of others. Thus, in a collective, at each instant there is the immediate experience of each individual and the immediate experience that is partially consensual between them.

The hypothesis of the activity-sign. The notion of the activity-sign as it has developed within the framework of the course-of-action research program results from the theoretical connection between the hypothesis of enaction and the hypothesis of the thought-sign : all activity is cognitive, and all cognition is a sign or a concatenation of signs, such that activity is conceived as a permanent construction of meanings (or meaning-making), and more precisely as a semiosis. The course-of-action program also assumes two interrelated levels of activity meaning. At the local level, the flow of activity can be broken down into units of elementary meaning. The activity is viewed as the sequence of these units. They are said to be elementary because they correspond to the smallest units of meaning for the actor. But the flow of activity also presents more global levels of organization that encompass the elementary units. Thus, documenting the course of action also consists of first identifying the elementary units and then reconstructing, step by step, their sequence and embedding in larger entities.

The hypothesis of the multiplicity (and complexity) of the constraints and effects of human activity. To these first three hypotheses is added a fourth explanatory hypothesis : the hypothesis of the multiple (and complex) constraints and effects of activity on the body, environment, and culture. Documentation of these activity constraints/effects may be enriched by observations related to the body (e.g., physiological variables or fatigue states), environment (e.g., interfaces, material objects, spatial organization, behaviors of other actors), and culture (e.g., social norms, cultural dynamics, elements of material culture). Three types of effects are investigated in course-of-action studies: (1) actual effects - transformations in the body, environment, and culture - that subsequently constitute constraints for the activity giving rise to experience for the actor (or actors) (as part of the documentation of the course of action) ; (2) "potential" effects assessed/anticipated by the observer that will only be actualized in the event of an effective transformation of the actor's (or actors') situation (in relation to the design issues); and (3) sets of effects that can be documented by "external and additional" data and that have explanatory power for the activity in question (as part of the documentation of the course of in-formation; see below).

\section{Theoretical objects within the course-of-action program}

30 Theoretical objects have been derived from these fundamental hypotheses, with the theoretical objects being the reductions in activity (individual or collective) that (1) relate to a precise part of the activity, and (2) make it possible to meet the criteria of scientific rigor and practical relevance. Studies included in the course-of-action 
program mobilize theoretical objects to account for individual-social activity (courses of experience, courses of action, courses of in-formation and courses of life related to a practice) (Table 1).

Table 1. Theoretical objects related to individual activity in the theoretical and methodological course-of-action framework

Theoretical object

Description

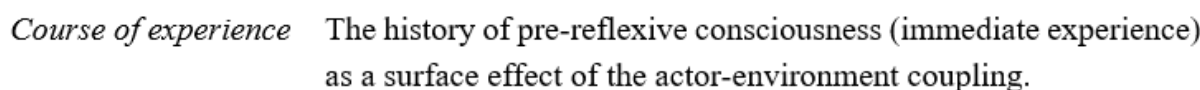

Course of action The history of pre-reflexive consciousness (immediate experience) to which are added the constraints and effects in the actor's body, environment and culture.

Course of in- The whole of the asymmetric interactions between the actor and formation his or her environment, whether or not it gives rise to pre-reflexive consciousness (immediate experience).

Course of life in Long-term examination of the activity that gives rise to prerelation to a practice reflexive consciousness (immediate experience) within the (or project) framework of the practice and shared with other practices.

31 As these objects allow collective activity to be approached only in a limited way, ${ }^{12}$ the course-of-action program also proposes the description of social-individual or collective activity through the articulation of individual-social activities (collective articulation of courses of experience, courses of action, courses of in-formation, and courses of life related to a practice) (Table 2). 
Table 2. Theoretical objects related to collective activity in the theoretical and methodological course-of-action framework

\begin{tabular}{|c|c|}
\hline Theoretical object & Description \\
\hline $\begin{array}{c}\text { Collective articulation } \\
\text { of the course of } \\
\text { experience }\end{array}$ & $\begin{array}{l}\text { Used to document the collective construction of consensual } \\
\text { meaning among several actors, each with their situational interface } \\
\text { (that is, the construction of both the "consensual meaning" at each } \\
\text { instant and "one's own world" for each of them). }\end{array}$ \\
\hline $\begin{array}{l}\text { Collective articulation } \\
\text { of the course of action }\end{array}$ & $\begin{array}{l}\text { Used to document the collective construction of consensual } \\
\text { meaning, with its constraints and effects, among several actors, } \\
\text { each with their situational interface. }\end{array}$ \\
\hline $\begin{array}{l}\text { Collective articulation } \\
\text { of the course of in- } \\
\text { formation }\end{array}$ & $\begin{array}{l}\text { Used to document the collective construction of consensual } \\
\text { meaning among several actors, each with their situational interface } \\
\text { and its articulation with different non-meaningful dimensions that } \\
\text { nevertheless play an essential role in the construction of collective } \\
\text { activity (cultural, dynamic interactional, or perceptual-motor } \\
\text { dimensions, or technical objects, depending on the case). }\end{array}$ \\
\hline $\begin{array}{l}\text { Collective articulation } \\
\text { of the course of life in } \\
\text { relation to a practice } \\
\quad \text { (or project) }\end{array}$ & $\begin{array}{l}\text { Used to document the long-term collective construction of } \\
\text { knowledge/know-how, skilled performance, works by several } \\
\text { actors, each with their situational interface. }\end{array}$ \\
\hline
\end{tabular}

\subsection{Theoretical object: the course of experience}

The course of experience constitutes all the elements of a situation that are relevant for the actor (his or her own world). Theureau (2006) defines it as "the actor's meaningmaking of his activity as it unfolds, or the history of the actor's pre-reflexive consciousness, or the history of this 'showable, tellable and commentable' that accompanies his activity at all times" (p. 48). This theoretical object concerns the intrinsic organization of the activity giving rise to experience. This experience is made up of the overt actions or communications that the actor considers meaningful accompanied not only by interpretations and feelings, but also by perceptual and mnemonic judgments. The analysis of the course of experience is based on the expression of pre-reflexive consciousness, and it can thus be described as units of meaning encased one in the other, with actions, communications, interpretations, emotions, feelings, recollections, etc. constituting a continuous flow.

\subsection{Theoretical object : the course of action}

This theoretical object is used to describe the actor's activity by giving primacy to prereflexive consciousness and thus to the course of experience. As opposed to an analysis of a course of experience, however, analysis of the course of action implies complementing the "showable, tellable, and commentable" with the observer's documentation of the constraints and effects of the course of experience (in the actor's body, environment, and culture). The course of action thus designates the connection between a course of experience and an extrinsic description. This description is termed 
extrinsic in that it is a circumscribed description of the external elements that are "relevant" for the observer referring to the course of experience.

\subsection{Theoretical object : the course of in-formation}

34 The course of in-formation is an account of the whole dynamic of asymmetric interactions between the actor and the environment, whether or not they give rise to pre-reflexive consciousness. It therefore involves documenting the elements that overrun the activity that can be shown, told and commented on but that are relevant in a comprehensive way. To be admissible or acceptable, a description of this theoretical object must be based on the conjunction of data from pre-reflexive consciousness (and therefore the course of experience) and observational data concerning the activity that did not give rise to experience for the actor.

\subsection{Theoretical object : the course of life related to a practice (or a project)}

This theoretical object accounts for the continuity of the courses of experience, action and in-formation during discontinuous practices and extending over larger temporal spans (and time shared with other practices). In other words, it is used to build links between episodes of activity emerging at different times but related to a given practice or project.

Each of the theoretical objects described above provides access to and sheds light on a particular aspect of activity. However, we should note two points here. First, the theoretical objects we call the course of experience, the course of action, and the course of in-formation (and their collective articulation) are cumulative (no documentation of the course of action without documentation of the course of experience, no documentation of the course of in-formation without documentation of the course of action). Second, these theoretical objects have in common the aim of documenting the time course of activity and its transformations (in interactions with the environment) by giving primacy to the history of the actor's or actors' pre-reflexive consciousness and complementing this with more or less extensive documentation of the effects and constraints in the body, environment, and culture.

\section{The observatory and the methodological workbench for course-of-action research}

The fundamental assumptions of the course-of-action program have given rise to a methodological development that is original and yet related to other programs. The methodological workbench of the course of action brings together a set of tools and methods that contribute to the development and refutation (or not) of a set of empirical hypotheses on activity. Together with the ontological and epistemological hypotheses on which it is based, it constitutes the research program observatory.

The expression of pre-reflexive consciousness can be considered or may need to be considered with different classes of methods, the first of which are the variants of the simultaneous, immediately postponed and interruptive verbalization methods (added 
to the "natural" verbalizations - that is, unprovoked - during the activity of spontaneous thinking out loud and verbal communications). Under certain conditions (precise instructions, questioning methods, participant training, etc.), these methods are relevant and economical ways of documenting pre-reflexive consciousness, such as during the unfolding of an event or just after its completion.

However, in many cases, the "controlled" expression of pre-reflexive consciousness cannot occur in the moment without distorting the activity under study. For this reason, through supplementary epistemological hypotheses, the course-of-action research program has contributed to developing, popularizing and specifying two methods for constructing data: self-confrontation interviews and reenactment interviews with material traces..$^{13}$ Both methods aim to document a posteriori the history of pre-reflexive consciousness (or that which is showable, tellable, commentable) and in a "sufficiently controlled" way by relying on a dynamical resituation based on traces of the activity. More generally, these methods help document an activity that gives rise to pre-reflexive consciousness in a given period of time.

\subsection{Expression of pre-reflexive consciousness : self-confrontation and situational analysis}

The self-confrontation and reenactment interviews can be distinguished mainly by the types of traces that are used. In the self-confrontation interview (Theureau, 2010), the traces are generally video recordings of the actors' in situ activity. The researcher confronts actors with video traces of their activity and invites them to explain, show, mimic, tell and comment on elements that are meaningful to them. During the selfconfrontation, the actors are engaged in an interaction aimed primarily at "re-living" the past activity.

In the reenactment interview, the traces are essentially discrete and material traces of the actor's past activity, traces left in the environment by the activity, or traces related to the successive transformations in the environment (Donin \& Theureau, 2007). This method is an extension of the principles and achievements of the self-confrontation and requires the constitution, dating and serialization of the material traces. These traces replace the video recording of behavior in the self-confrontation. The reenactment interview through material traces is particularly useful when recording is impossible or when activity is documented over long and discontinuous periods. Unlike the self-confrontation, the reenactment interview through material traces is still underdeveloped.

The choice or articulation of these methods is made in relation to the characteristics of the activity, the environment and the research, as well as various circumstantial factors. Reenactment interviews through material traces make it possible to circumvent the constraints of video recordings, analyze longer time spans, and document empirically and a posteriori, for example, the experience of actors during unforeseen events.

43 Two clarifications should be made : the first concerns the use of these methods for the analysis of collective activity, and the second concerns the use of ethnography as a complement. In the course-of-action research program, primacy is given to the individual rather than collective expression of pre-reflexive consciousness. Greater importance is given to individual expression to prevent the actors from entering into 
social games among themselves and with the researchers. The second concerns the use of ethnographic methods. The self-confrontation and reenactment interviews through material traces take place only after a preliminary ethnographic work (see Azéma, Secheppet, \& Mottaz; Theureau, in this issue) that prepares for their implementation and provides a common background between the actors and researchers, thereby contributing to the ethical conditions of research.

The course-of-action workbench is constantly evolving and is by no means set in stone. The objectives of this issue are to illustrate the different ways the workbench can be implemented, to show and explain the tradeoffs between the methods (in relation to the characteristics of the activity, environment, research, and various circumstantial factors), and to point out their advantages, disadvantages, and complementarities (see Azéma, Secheppet, \& Mottaz ; Terré, Sève, \& Huet in this issue).

\subsection{The conditions for the expression of pre-reflexive consciousness}

The methods described above involve making auxiliary hypotheses (which can be described as epistemological) about the material and technical conditions to be implemented in order to guarantee an effective, although always partial, expression of the pre-reflexive consciousness of actors.

The first set of hypotheses relates to the conditions of observing and recording during an activity and/or the various kinds of material traces it generates and/or constructible. These hypotheses make it possible to specify: (1) the criteria for choosing tools for observing and recording an activity (or behavior) in a situation and the types of material traces of it ; (2) the methods for using these hypotheses in relation to the characteristics of the activities being studied and the theoretical objects ; and (3) the various ways for the researchers to avoid disrupting the activity of the actors in situ, or to do so in a controlled manner, by implementing various principles and benefiting from the actors' cooperation and familiarization with the observation and recording system.

The second set of hypotheses concerns : (1) how to "de-situate" actors from both their present situation (especially including the researcher) and the verbal communication situations they are used to (self-serving, agreed-upon speech, evaluative situations, or with hierarchical relations), and (2) how to avoid the emergence of new awareness during the self-confrontation or reenactment interview in relation to the situation under study. "De-situating" the actors implies "re-situating" them by putting them back in the past situation under study and maintaining them there, and thus not "desituating" them anew through inappropriate questioning. Regarding new awareness, the interviewer, through instructions and prompts, must encourage the explicitation and amplification of the past experience by helping the actor to "relive" it and not adopt more distant attitudes, judgments, explanations, or generalizations. The methods for the expression of pre-reflexive consciousness have nothing to do with awarenessraising and give rise to a type of "paradox" : via the video recordings or structured traces related to their activity, actors are put in a position where they would be able to spread out a reflective practice but are asked not to do so. Instead, they are asked to limit themselves to expressing only their pre-reflexive consciousness at the time of the past activity. 
As for any research observatory, the course-of-action observatory developed in close relation with technical advances in, for example, video recording devices, miniaturized and portable devices for recording physical data, and even simulation tools. This close relationship with technical advances is reflected in the improvements and new developments in the observatory/workbench: recording of $360^{\circ}$ videos (with consequences for reenacting the situation), collecting written traces with digital pens, automatic recording with Swivl@-type devices, USB dictaphones worn around the neck, and subjective cameras. The procedures for expressing pre-reflexive consciousness have also developed, particularly for the reenactment interview with material traces (digital traces, written traces left by the actor's activity, produced by the researcher, digital traces and data, photo traces, the actor's self-produced photo or video traces) and even the reenactment interview with material traces left in the actor's body (see Terré, Sève, \& Huet, in this issue). Last, although they may have borrowed or are likely to borrow from methods developed within the framework of other research programs, the course-of-action methods for constructing data on actors' bodies, environments and cultures remain essentially open-ended: they are not merely limited to being articulated with physiological, biomechanical and neurological data (see Adé, GalPetitfaux, Rochat, Seifert, \& Vors, in this issue) and ethnography (see Azéma et al., in this issue), but they also, for example, have evolved to show variations in the selfconfrontation interviews to favor the documentation of constraints and extrinsic effects (Durand, Goudeaux, Poizat, \& Sarmiento, 2020). In one notable example, a collective configuration is used with two observer-interlocutors positioned in a triangle pattern.

These methodological advances would benefit from investigations today within the framework of a technological research program related to the course-of-action workbench - that is, situations of data construction and the analysis of courses of action. This technological program might include, for example, not only older studies using simulation in activity research (Theureau, 1997b, 2000), but also studies on digital tools for research (data collecting, data processing, modeling) (Perrin, Menu, Theureau, \& Durand, 2011; Schmitt \& Aubert, 2016). Indeed, even though the methodological advances in the course-of-action program have been numerous, they have not led to the design of specific digital tools for processing and analyzing data. This undoubtedly is a direction for future research.

\section{Semiological framework}

The semiological framework for the course-of-action program was inspired by the "thought-sign" hypothesis according to which humans think and act by signs (Peirce, 1978). Here the sign is defined as a triadic relation "from a representamen (R) [Actual] to an object (O) [Potential] through the mediation of an interpretant (I) [Virtual]" (Peirce, 1978, cited by Theureau, 2004, p. 139). Theureau (2004) added a fourth component, the Unit of the course of experience (U), to the Peircean sign as the first step, thus proposing a tetradic sign. This semiological framework makes it possible to account for the dynamics of the transformation of activity by considering the lived experience of actors at a specific moment. 


\subsection{The components of the sign and their evolution}

The tetradic sign (Theureau, 2004) was then completed and enriched to become the hexadic sign (Theureau, 2006). This shift from the tetradic to the hexadic sign was mainly motivated by the need to improve the empirical documentation of learning processes. Indeed, although it is possible to use the tetradic sign to address knowledge construction, it quickly shows its limits in the field. Table 3 shows the evolution of the concept of sign.

Table 3. Evolution of the notion of sign in the course-of-action research program

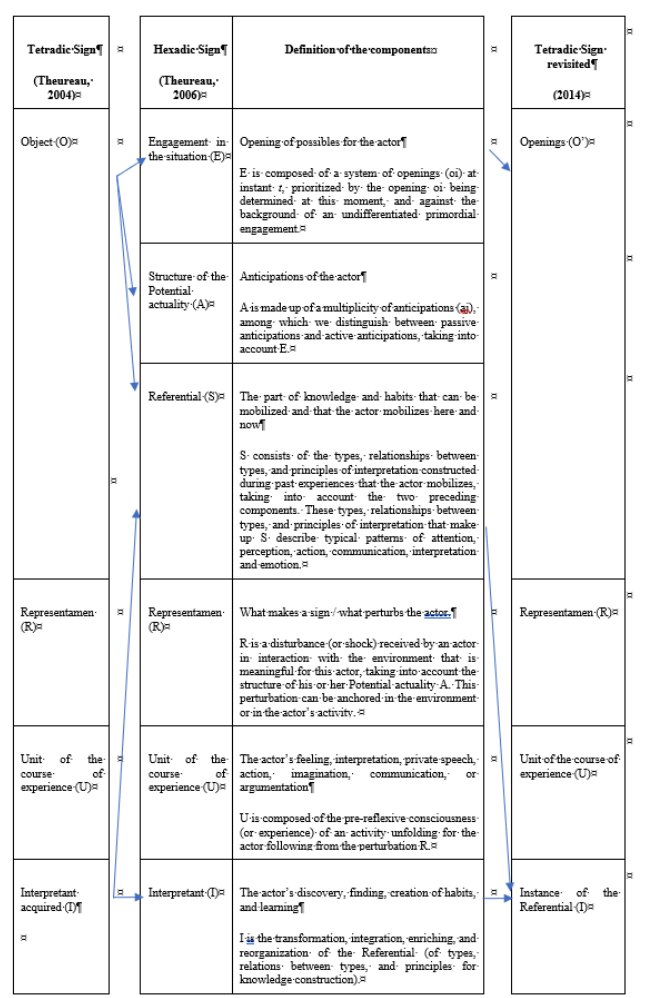

52 In the hexadic sign, the Engagement in the situation " $E$ " is associated with an emotional tone and emerges from the history of past interactions, delimiting both the anticipations arising from these past interactions and the possibilities of future perturbations. By hypothesis, the Engagement in the situation circumscribes the anticipations or expectations of the actor at time $t$. The Potential Actuality "A," which like "E" has an emotional tone, emphasizes the relationship to the future and connects the immediate experience to an immediate future. The Engagement "E" and the Potential Actuality "A" of actors at a certain moment are linked to habits, knowledge, and types. These habits, knowledge, and types, when mobilized in a given situation, constitute the Referential "S," which "rehabilitates the habitual," 14 but also refers to the situation and a family of situations experienced by the actors.

The Representamen " $R$ " corresponds to a perturbation (or shock) that is meaningful for actors given their Potential Actuality “A." Perturbations can trigger perceptual (perceiving something), proprioceptive (bodily expression) and mnemonic (remembering something) judgments. This component is in a dynamic relationship with the Engagement "E" in the sense that it defines how the perturbation interests the 
actor. The Representamen " $R$ " is also in dynamic relationship with the Potential Actuality " $\mathrm{A}$ " that defines the degree of perturbation (or gradient of surprise) from the selection of one anticipation among others.

The Unit of the course of experience " $\mathrm{U}$ " corresponds to the actor's activity resulting from the perturbation "R." It is not limited to actions and diagnoses but also includes "states of mind, feelings, communications, and all kinds of inferences and interpretations (...) ; it is a 'response,' but one that is elaborated from much more than simple stimuli" (Theureau, 2006, p. 296).

The Representamen "R" and the Unit of the course of experience " $U$ " are the components of the hexadic sign that translate the hypothesis of activity as a structural actor-environment coupling. Theureau (2006) assumes that it is impossible to conceive of a theory of cognition that is not a theory of situated learning, more particularly of a permanent transformation of the structural actor-environment coupling. The Interpretant "I" reflects the hypothesis according to which there is a permanent transformation (to different degrees) of the habits, types of knowledge, and types of actors (transformation or emergence of types). Thus, this component takes into account that all activity is accompanied by learning, development, appropriation, discovery, finding, and creation of habits. The Interpretant " $\mathrm{I}$ " enriches and transforms the Referential "S." This Referential "S" is also enriched by the Representamen " $R$ " and the Unit of the course of experience "U."

\subsection{Implementation of the semiological framework and modeling aims}

Course-of-action research has essentially implemented this semiological theoretical framework as applicative-inventive modeling. The studies very often aim to build specific or local analytical empirical models that are specific to the field in question. This has resulted in multiple models : the activity of high-level table tennis players, the activity of railway traffic controllers, collective activity during preservice teacher counseling sessions, the transformation in the activity of preservice teachers, or activity within the framework of training systems such as the Théâtre du Vécu (the Theater of Experience ; see Flandin, Salini, Drakos, \& Poizat, in this issue).

Analytical empirical models are essential for work analysis and ergonomics (Amalberti, de Montmollin, \& Theureau, 1991) and, more generally, for activity analysis and the various associated forms of design/engineering, whether in ergonomics, training, management, or museography. They are made up of a system of more or less abstract descriptive categories. Through the subdivision of empirical data that they allow, these descriptive categories both concretize the categories specific to a particular empirical domain and help reveal the specific features of this domain. Once this empirical model has been produced, practical propositions for transformation/design become possible, as well as intermediate or practical models, and even complementary synthetic models. We will return to this last perspective.

Not all course-of-action studies, particularly those that are carried out under constrained conditions, lead to or even pursue the aim of producing analytical empirical models. They thus implement the semiological theoretical framework in a comprehensive, applicative-inventive way. This is particularly the case, for example, with research on the activity of travelers at the Gare du Nord train station in Paris, the 
activity of nuclear reactor monitoring for incidents-accidents by the reactor operators, or even the activity of judicial officers. Let us add that the semiological theoretical framework can also be implemented in a strictly applicative manner. This implies that one accepts as valid the semiological notions and hypotheses and simply seeks to apply them in a given empirical domain. This is obviously less interesting from a research perspective, but perhaps "sufficient" in the context of certain design or transformation projects.

The modeling issues suggest two series of questions within the framework of the course-of-action program. First, should the analysis of activity be articulated with a synthetic modeling approach that uses mathematical (particularly from dynamic theories), diagrammatic, or simulation tools, and if so, under what conditions (see Guilbourdenche; Haradji, in this issue)? Second, would these synthetic modeling approaches (mathematics, diagrammatic, simulation) also benefit from being articulated with analyses of activity and the analytical empirical models produced? Recent research shows that course-of-action studies can lead to the construction of both : (1) descriptive categories related to a given empirical domain, therefore of a local analytical empirical model, and (2) a synthetic empirical model. More generally, this research makes it possible to argue for the primacy of the analytical method over the synthetic method. It particularly shows that the first stages of synthetic methods benefit from being initiated, completed, or even replaced by an analysis of activity and that it is very often relevant for building an analytical empirical model before constructing a synthetic model (mathematical, diagrammatic, or simulation-based) (see Haradji, in this issue).

\section{Design as part of the technological course-of-action research program}

60 As indicated in the brief historical review introducing this article, design issues (approaches, tools, and methods of participation) have been at the heart of the researchers' preoccupations in the course-of-action research program from the very beginning, and they continue to be so. Examples would be the early writings on the paradox of design ergonomics (Pinsky, 1992 ; Theureau \& Pinsky, 1984) or the paradox of autonomy for computer design (Theureau \& Jeffroy, 1994). Nevertheless, we will limit ourselves here to listing the essential and differentiating aspects without going into detail : the models for design, design as situation engineering (or in other words designing in terms of situation), and notions of both aid and appropriation.

\subsection{Models for design}

61 The first element concerns the practical models that contribute to design. Unlike empirical models that have an epistemic function, practical models have the unique function of contributing to action/transformation. To be effective, they must necessarily have some empirical validity, but this does not need to be made explicit or even based on serious empirical analysis. But some of these practical models nevertheless receive input from empirical research or are even the product of empirical research, sometimes to the point of being inseparable from it. Such empirically driven practical models are of the most interest to researchers, who see 
their contribution to the engineering/designing of situations (ergonomics, training, management, etc.) and are encouraged in a technological program. In this sense, we can refer to "technological practical models." These technological models are central to design. They are indeed sometimes pivotal in linking analytical empirical models (related to activity) with aims and issues specific to technical development (Haué, 2004 ; Haradji, in this issue). Pivotal models are inherently hybrid or frontier and imply collaborative design involving multiple actors on the basis of analytical empirical models. Pivotal models are essential points of passage and encounter because : (1) they connect the present ("what is being done") and the future ("what will be done"), (2) they carry the traces of empirical models, and (3) they make design activity possible and thus prefigure a future or virtualities. The shift from an empirical model to a pivotal model, however, is not a simple translation. For this reason, the technological course-of-action program focuses on specifying the conditions for switching from one model to the other through the development of its workbench.

\subsection{Design as situation engineering (and in terms of situation)}

The second element concerns the design objectives and makes it possible to specify/ operationalize a course-of-action-centered design (or meaning-making-centered design), that is, one that is consistent with both enaction and experience. Although the theoretical and methodological framework of the course of action can be mobilized advantageously from a UX design perspective, the course-of-action design approach historically developed as an extension of human-centered design while continuing to move toward a conception more oriented by activity and meaning-making rather than by humans (Pinsky, 1990; Pinsky \& Pavard, 1984). Perhaps the main disruptive characteristic of course-of-action-centered design is that it is structured as situation engineering. Such situational engineering is opposed to artifact engineering and is part of a broad and transversal activity "policy" (including in a project of society) (Theureau, 2019). The essential differences between situation and artifact engineering are: (1) the design, transformation and development of technical, organizational, cultural and educational eco-systems in which activity takes place or emerges, and not just artifacts ; (2) the participation of actors, active and "clearly heard," in the study and design of their environments and in the transformation of their own situations using appropriate methods, tools and procedures ; and (3) the relationship that design must maintain with the analysis of human and social beings as activities rather than facts (Theureau, 2019). The artifact is seen only as part of the transformation of the future situation. The design in terms of situation must always articulate technical, organizational, cultural, and educational designs. Depending on the design project, the focus may be on one of these components, but always "in relationship" to the others.

\subsection{The concepts of aid and appropriation}

The third element concerns the specification of design objectives and design objects in terms of aid and appropriation. The course-of-action research program positioned itself very early on for the design of aid situations and not artifacts, which were thought of as prostheses, replacing actors by carrying out tasks for them (Pinsky, 1992 ; Theureau \& Jeffroy, 1994). In the field of design, there is a certain confusion around the notion of aid, to the point where the use of this notion has become generalized to a set 
of extremely heterogeneous situations and tools: prostheses for people with disabilities, expert systems, the "help" function in software intended for the general public, or driver assistance systems and automation tools to keep a car in its lane as an aid to driving. This confusion results in part from the proximity of the concept of aid to other concepts, such as assistance. For the studies and projects carried out within the framework of the course-of-action design approach, a relationship of aid is assumed to be established between actors and technique when the appropriation and use of a technical device open a horizon onto unprecedented possibilities (actions, perceptions, and experiences) in the actor-environment coupling. The technique, once appropriated, opens up, enables, or empowers possibilities for action by the actors and through their relationship with the environment. This last point has led the program to now propose the situation of appropriation as a design object. In the design field, the concept of appropriation is traditionally used to account for the way in which an artifact is adopted, adapted, tinkered with, arranged, and integrated into the daily practices of actors. Within the framework of the course-of-action program, appropriation is defined as a triple process of integration (in-situation/in-corporation/ in-culturation), making it possible to describe the absorption of novelty and the transformation of actor-environment coupling, whether in relationship to technical objects or another actor (or group of actors). By making the appropriation situation a design object, the aim is to target/anticipate this triple integration and the associated individuation process within the framework of the design. This design object (1) makes it possible to think about design issues as a coupling of appropriation/alienation, (2) takes the full measure of the anthropologically constitutive and constituent role of technique, (3) imposes developmental questions in all design projects, and (4) opens on to the design of social-technical-organizational environments and/or promising training situations with mutual appropriation as a way to support collective activity. The objective of design is therefore twofold since it involves supporting the activity that gives rise to actors' experience and causes a transformation in the elements that are meaningful for them in their articulation with the environment, based on the strong probability that a process of individual or collective appropriation and individuation will begin.

\section{New frontiers for the course-of-action research program and current research}

Many possibles for future research are open for and within the framework of the course-of-action program with regard to problems that are still poorly defined, hypotheses that need to be empirically tested, further development of the observatory and workbench, and new frontiers that might fruitfully be explored. Although we will not detail all the possibles open for research, we do refer readers to the various works by Theureau (2006, 2015a, 2019). Here we will instead specify one of these openings particularly discussed in this issue and currently receiving considerable focus: the extension toward multi-scale and multi-level analyses of activity in organic relation with the engineering of situations, which is also being extended. Indeed, this extension poses many challenges and questions for course-of-action studies that (1) have mainly focused until now on the level of activity giving rise to pre-reflexive consciousness for one or more actors, and (2) have focused only on limited spaces, limited time horizons 
and limited sizes of organizational and artifactual environments. Moving toward these analyses will require specific theoretical objects such as the course of life as it relates to a practice (or a project) or the course of in-formation. It will also be crucial to enhance and creatively mobilize the methodological workbench (by an extensive return to ethnography, historical ethnographic-type surveys, dynamic reenactment interviews, and methods specific to other programs).

Developing multi-scale and multi-level analyses also involves adding hypotheses to study the relationships between different levels of organization and the meaning of an activity. On this last point, the course-of-action program assumes a "star * statement" between the activity giving rise to pre-reflexive consciousness (which we might call by convention the "average level" of activity) and two series of phenomena: (1) a lower level of neuronal, motor or interactional dynamics, and (2) a higher level of historical, artifactual, social, cultural, organizational and political dynamics that are seen as the synthetic propensity of activity for a set of actors, over a given time period, and for a given spatial and organizational environment (Theureau, 2019, p. 40). More precisely, we should perhaps refer to a multi-level analysis of human activity in a "star * statement." The hypothesis structuring this multi-level analysis project is that different series of phenomena (lower, middle, higher) maintain a triple relation of inclusion (of the infra level within the supra level), emergence (of the supra level from the infra level) and constraint (of the supra level on the infra level).

The same is true for time scales. It is possible to describe activity on distinct, consistent and self-sufficient time scales, ranging from elementary and local micro-actions to larger quanta (project, biography, existence, generations). These scales have relatively independent levels of organization and present distinct dynamics. They have specific meanings for the actors. There is always a scientific and/or practical grounds for describing activity at a given level of organization but keeping the focus on a single scale carries the risk of being blinded to the underlying organizational levels and a tendency to reify the above-ordered levels of organization. For this reason, multi-scale and multi-level analyses of activity in a "star * statement" are a necessary evolution for the course-of-action research program.

This multi-scale and multi-level research perspective has meant expanding the current frontiers of the course-of-action program and borrowing from and debating with the researchers from other programs - yet all the while maintaining the hypothesis of the irreplaceability of activity giving rise to experience : toward history in the direction of the micro-history of activity and historical studies as a re-activation of past thought ; toward cultural anthropology with the perspective of better taking into account cultural dynamics; toward the organizational sciences to account for organizing; toward neuro-phenomenology to document neuronal micro-dynamics, while also continuing the development of an enactive phenomenological psychology. This perspective of the multi-level analysis of activity makes the course-of-action research program open at both ends, toward series of higher and series of lower phenomena, and militant in the pursuit of a local transdisciplinarity delimited by the nature of the questions addressed and the hypotheses about activity. 


\section{BIBLIOGRAPHY}

Adé, D., Veyrunes, P., \& Poizat, G. (2009). Les objets dans l'activité interindividuelle en classe : l'exemple de leçons d'Éducation Physique et Sportive et de géographie. Travail et Apprentissage, 3, 124-139.

Amalberti, R., de Montmollin, M., \& Theureau, J. (Eds.). (1991). Modèles en analyse du travail. Bruxelles : Margada.

Antipoff, R., \& Lima, F. (2017). Didática professional e teoria do curso da ação : diferentes contribuições para a formação professional. Revista Ação Ergonômica, 12(2). Recuperado de http:// www.abergo.org.br/revista/index.php/ae/article/view/734/313

Arripe-Longueville (d'), F., Saury, J., Fournier, J., \& Durand, M. (2001). Coach-athlete interaction during elite archery competitions: An application of methodological frameworks used in ergonomics research to sport psychology. Journal of Applied Sport Psychology, 13(3), 275-299. https://doi.org/10.1080/104132001753144419

Bertone, S., \& Chaliès, S. (2015). Construire un programme de recherche technologique sur la formation des enseignants : choix épistémologiques et théoriques. Activités, 12(2). https:// doi.org/10.4000/activites.1088

Bonasio, R., Fondeville, B., \& Veyrunes, P. (2015). Accompagnement d'une équipe enseignante de l'école primaire : l'analyse de l'activité comme aide à l'appropriation d'une culture commune. Éducation et socialisation, 38. https://doi.org/10.4000/edso.1282

Bonasio, R., \& Veyrunes, P. (2016). Activité collective et apprentissages dans la pratique des devoirs. Éducation \& Formation, 304(1), 74-86. Récupéré sur http://revueeducationformation.be/ index.php?revue $=22 \&$ page $=3$

Bourbousson, J., Poizat, G., Saury, J., \& Sève, C. (2011). Description of the dynamic shared knowledge: an exploratory study during competitive sports interaction. Ergonomics, 54(2), 120-138. https://doi.org/10.1080/10413201003664657

Chaliès, S., Ria, L., Bertone, S., Trohel, J., \& Durand, M. (2004). Interactions between preservice and cooperating teachers and knowledge construction during post-lesson interviews. Teacher and Teaching Education, 20(8), 765-781. https://doi.org/10.1016/j.tate.2004.09.001

Clancey, W. (1993). Situated action : a neuropsychological interpretation response to Vera and Simon. Cognitive Sciences, 17(1), 87-116. https://doi.org/10.1207/s15516709cog1701_7

Daniellou, F. (2006). «Je me demanderais ce que la société attend de nous... ». À propos des positions épistémologiques d'Alain Wisner. Travailler, 15(1), 23-38. https://doi.org/10.3917/trav. 015.0023

De Moraes-Pires, M., \& Durand, M. (2011). L'inspection en sécurité au travail et les interventions d'urgence dans le bâtiment. Revue Économique et Sociale, 69(2), 23-32.

Dequaire-Falconnet, E. (2001). Modélisation de l'activité individuelle et collective dans les perspectives d'une prévention des risques des installations dès la conception. Thèse de doctorat, Université de Technologie de Compiègne, Compiègne.

Dieumegard, G. (2011). Dimensions cognitives et sociales dans l'étude de l'activité des élèves : La représentation comme inférence individuelle-sociale dans le cours d'expérience. Éducation \& Didactique, 5(3), 33-60. https://doi.org/10.4000/educationdidactique.1103 
Dieumegard, G., Saury, J., \& Durand, M. (2004). L'organisation de son propre travail : une étude du cours d'action de cadres de l'industrie. Le Travail Humain, 67(2), 157-179. https://doi.org/10.3917/ th.672.0157.

Donin, N., Goldszmidt, S., \& Theureau, J. (2009). Organiser l'invention technologique et artistique ? L'activité collective de conception conjointe d'une œuvre et d'un dispositif informatique pour quatuor à cordes. Activités, 6(2). https://doi.org/10.7202/017909ar

Donin, N., \& Theureau, J. (2007). Theoretical and methodological issues related to long term creative cognition: the case of musical composition. Cognition, Technology \& Work, 9(4), 233-251. https://doi.org/10.1007/s10111-007-0082-z

Dougherty, J. (Ed.). (1985). Directions in cognitive anthropology. Urbana: University of Illinois Press.

Durand, M. (2008). Un programme de recherche technologique en formation des adultes : Une approche enactive de l'activité humaine et de l'accompagnement de son apprentissage/ développement. Éducation et Didactique, 2(3), 97-121. https://doi.org/10.4000/ educationdidactique.373

Durand, M. (2013). Construction of dispositions and development of human activity. A theoretical framework illustrated by the case of a novice manager. International Journal of Lifelong Education, 32(1), 39-55. https://doi.org/10.1080/02601370.2012.734490

Durand, M., Goudeaux, A., Poizat, G., \& Sarmiento, J. (2020). Des films pour analyser le travail et documenter des situations de formation. Images du Travail - Travail des Images, 8. Récupéré sur https://imagesdutravail.edel.univ-poitiers.fr :443/imagesdutravail/index.php ?id =2620.

Durand, M., Saury, J., \& Veyrunes, P. (2005). Relações fecundas entre pesquisa e formação : elementos para um programa. Cadernos de Pesquisa, 35(125), 37-62. https://doi.org/10.1590/ S0100-15742005000200004

Durand, M., \& Veyrunes, P. (2005). L'analyse de l'activité des enseignants dans le cadre d'un programme d'ergonomie-formation. Les dossiers des Sciences de l'Éducation, 14, 47-60. https:// doi.org/10.3406/dsedu.2005.1208

Évin, A., Sève, C., \& Saury, J. (2015). L'histoire collective comme notion descriptive pour l'analyse de l'activité d'élèves engagés dans des situations de coopération en Éducation Physique. Activités, 12(2). https://doi.org/10.4000/activites.1080

Flandin, S., Poizat, G., \& Durand, M. (2018). Improving resilience in high-risk organizations: principles for the design of innovative training situations. Development and Learning in Organizations: An International Journal, 32(2), 9-12. https://doi.org/10.1108/DLO-03-2017-0027

Flandin, S., \& Ria, L. (2014). Un programme technologique basé sur l'analyse de l'activité réelle des enseignants débutants au travail et en vidéoformation. Activités, 11(2). https://doi.org/ 10.4000/activites.970

Flavier, E., Bertone, S., Hauw, D., \& Durand, M. (2002). The meaning and organization of physical education teachers' actions during conflict with students. Journal of Teaching in Physical Education, 22(1), 20-38. https://doi.org/10.1123/jtpe.22.1.20

Geslin, P. (2006). Le politique et le scientifique dans la pratique anthropotechnologique. Travailler, 15(1), 149-163. https://doi.org/10.3917/trav.015.0149

Geslin, P. (2012). La circulación de los hombres y las técnicas : reflexiones sobre la antropotecnología. Laboreal, 8(2). https://doi.org/10.4000/laboreal.6533 
Goldszmidt, S., \& Theureau, J. (2010). Conception de situations d'assistance à l'écoute musicale et analyse de l'activité de composition musicale. In G. Vallery, M.-C. Le Port, \& M. Zouinar (Eds.), Ergonomie et conception de produit et de services médiatisés (pp. 157-182). Paris : PUF.

Guibourdenche, G., Vacherand-Revel, J., Fréjus, M., \& Haradji, Y. (2015). Analyse de contextes d'activité domestique pour la conception de systèmes diffus énergétiquement efficients. Activités, 12(1). https://doi.org/10.4000/activites.994

Haradji, Y., \& Faveaux, L. (2006). Évolution de notre pratique de conception (1985-2005). Activités, 3(1). https://doi.org/10.4000/activites.1852

Haué, J.-B. (2004). Intégrer les aspects situés de l'activité dans une ingénierie cognitive centrée sur la situation d'utilisation. Activités, 1(2). https://doi.org/10.4000/activites.1285

Haué, J-B., Le Bellu, S., \& Barbier, C. (2020). Le véhicule autonome : se désengager et se réengager dans la conduite ? Activités, 17(1). https://doi.org/10.4000/activites.4987

Hauw, D., \& Mohamed S., (2015). Patterns in the situated activity of substance use in the careers of elite doping athletes. Psychology of Sport \& Exercise, 16(2), 156-163. https://doi.org/10.1016/ j.psychsport.2013.09.005

Horcik, Z., Savoldelli, G., Poizat, G., \& Durand, M. (2014). A phenomenological approach to novice nurse anesthetists' experience during simulation-based training sessions. Simulation in Healthcare, 9(2), 94-101. https://doi.org/10.1097/SIH.0000000000000021

Hutchins, E. (1995). Cognition in the wild. Cambridge: MIT Press.

Hutchins, E. (2010) Imagining the cognitive life of things. In L. Malafouris \& C. Renfrew (Eds.), The cognitive life of things: recasting the boundaries of the mind (pp. 91-101). Cambridge: McDonald Institute for Archaeological Research.

Jeffroy, F. (2003). En hommage à Antoine Laville. Bulletin de la SELF, Juillet.

Koyré, A. (1971). Études d'histoire de la pensée philosophique. Paris: Gallimard.

Lacomblez, M., Bellemare, M., Chatigny, C., Delgoulet, C., Re, A., Trudel, L., \& Vasconcelos, R. (2007). Ergonomic analysis of work activity and training: Basic paradigm, evolutions and challenges. In R. Pikaar, E. Konongsveld, \& P. Settels (Eds.), Meeting Diversity in Ergonomics (pp. 129-142). Amsterdam : Elsevier.

Lacomblez, M., \& Vasconcelos, R. (2009). Análise ergonómica da actividade, formação e transformação do trabalho : opções para um desenvolvimento durável. Laboreal, 5(1). https:// doi.org/10.4000/laboreal.10388

Lakatos, I. (1994). Histoire et méthodologie des sciences. Paris: PUF.

Lave, J. (1988). Cognition in practice: Mind, mathematics and culture in everyday life. Cambridge: Cambridge University Press.

Laville A., Teiger C., \& Duraffourg J. (1972). Conséquences du travail répétitif sous cadence sur la santé des travailleurs et les accidents. Rapport du Laboratoire de Physiologie du travail et d'Ergonomie 29, Paris : CNAM.

Leblanc, S., Ria, L., Dieumegard, G., Serres, G., \& Durand, M. (2008). Concevoir des dispositifs de formation professionnelle des enseignants à partir de l'analyse de l'activité dans une approche enactive. Activités, 5(1). https://doi.org/10.4000/activites.1941

Milner, J.-C. (1995). L'œuvre claire : Lacan, la science, la philosophie. Paris : Seuil. 
Motté, F., \& Haradji, Y. (2010). Construire la relation de service en considérant l'activité humaine dans ses dimensions individuelles et collectives. In G. Vallery, M.-C. Le Port, \& M. Zouinar (Eds.), Ergonomie et conception de produit et de services médiatisés (pp. 11-35). Paris : PUF.

Nello, É. (2017). Appréhender l'expérience et le cours d'existence de personnes malades chroniques sur des empans temporels longs : conception d'outils méthodologiques. Savoirs, 45(3), 67-86. https://doi.org/10.3917/savo.045.0067

Peirce, C. S. (1978). Écrits sur le signe. Paris : Seuil.

Perrin, N., Menu, J., Theureau, J., \& Durand, M. (2011). SIDE-CAR : un outil d'aide à l'analyse de l'activité selon le cadre théorique du cours d'action. Recherches Qualitatives, 30, 148-174. Récupéré sur http://www.recherche-qualitative.qc.ca/documents/files/revue/edition_reguliere/ numero30(2)/RQ_30(2)_Perrin-al.pdf

Pinsky, L. (1990). User activity centered design. In L. Berlinguet \& D. Berthelette, (Eds.), Work with display units (pp. 119-150). North-Holland : Elsevier.

Pinsky, L. (1992). Concevoir pour l'action et la communication : essais d'ergonomie cognitive. Berne: Peter Lang.

Pinsky, L. \& Pavard, B. (1984). What does real work analysis tell us for system design? In C. Van der Veer, M. Tauber, T. Green, \& P. Gorny (Eds.), Reading on cognitive ergonomics - Mind and computers (pp. 248-259). Berlin : Springer Verlag.

Pinsky, L., \& Theureau, J. (1982). Activité cognitive et action dans le travail (Tome 1 \& 2). Rapport du Laboratoire de Physiologie du travail et d'Ergonomie 73, Paris : CNAM.

Pinsky, L., \& Theureau, J. (1987). L'étude du Cours d'Action : Analyse du travail et conception ergonomique. Rapport du Laboratoire de Physiologie du travail et d'Ergonomie 88, Paris : CNAM.

Poret, C. Folcher, V., Motté, F., \& Haradji, Y. (2016). Concevoir pour le pouvoir d'agir ensemble au sein des organisations : le cas d'un processus commercial. Activités, 13(2). https://doi.org/ $10.4000 /$ activites. 2820

Ria, L., \& Leblanc, S. (2011). Conception de la plateforme de formation Néopass@ction à partir d'un observatoire de l'activité des enseignants débutants : enjeux et processus. Activités, 8(2). https://doi.org/10.4000/activites.2618

Rochat, N., Gesbert, V., Seifert, L., \& Hauw, D. (2018). Enacting phenomenological gestalts in ultra-trail running: An inductive analysis of trail runners' courses of experience. Frontiers in Psychology, 9, Article 2038. https://doi.org/10.3389/fpsyg.2018.02038

Rochat, N., Hauw, D., \& Seifert, L. (2019). Enactments and the design of trail running equipment: An example of carrying systems. Applied Ergonomics, 80, 238-247. https://doi.org/10.1016/j.apergo. 2018.07.002

Salini, D., \& Durand, M. (2012). L'activité des conseillers dans des situations d'information-conseil initial pour la V.A.E. : Des métaphores pour préfigurer l'avenir et s'engager dans l'inconnu. Carriérologie, 12(3), 367-384.

Salini, D., \& Durand, M. (2020). Overcoming a lived experience of personal impasse by creating a theatrical drama: An example of promoting resilience in adult education. In L. McKay, G. Barton, S. Garvis, \& V. Sappa (Eds.), Arts-based research, resilience and well-being across the lifespan (pp. 169-189). Palgrave Macmillan : Cham. 
Salini, D., Jaramillo, J., Goudeaux, A., \& Poizat, G. (2018). Profesiones de servicio y digitalización : implicaciones y sugerencias para la concepción de procesos de formación. Laboreal, 14(2). https:// doi.org/10.4000/laboreal.584

San Martin, J., Veyrunes, P., Martinic, S., \& Ria, L. (2017). Aportes del programa de investigación "curso de la acción" al análisis de la actividad de los profesores y a la formación. Revista perfiles educativos, 39(58), 168-185. Recuperado en https://dialnet.unirioja.es/servlet/articulo?

codigo $=6410606$

Sartre, J-P., \& Lévy, B. (1991). L'espoir maintenant. Lagrasse : Verdier.

Saury, J., Adé, D., Gal-Petitfaux, N., Huet, B., Sève, C., \& Trohel, J. (2013). Actions, significations et apprentissages en EPS : une approche centrée sur le cours d'expérience des élèves et des enseignants. Paris : Éditions EPS.

Schmitt, D. (2015). Apports et perspectives du programme de recherche « cours d'expérience » des visiteurs dans les musées. Nouvelles tendances de la muséologie, 43b, 249-261. https://doi.org/ $10.4000 /$ iss. 506

Schmitt, D., \& Aubert, O. (2016). REMIND, une méthode pour comprendre la micro-dynamique de l'expérience des visiteurs de musées. Revue des Interactions Humaines Médiatisées, 17(2), 43-70.

Schot, S., Flandin, S., Goudeaux, A., Seferdjeli, L., \& Poizat, G. (2019). Formation basée sur la perturbation : preuve de concept par la conception d'un environnement numérique de formation en radiologie médicale. Activités, 16(2). https://doi.org/10.4000/activites.4724

Sève, C., Poizat, G., Saury, J., \& Durand, M. (2006). Un programme de recherche articulant analyse de l'activité en situation et conception d'aides à la performance : un exemple en entraînement sportif de haut niveau. Activités, 3(2). https://doi.org/10.4000/activites.1353

Sève, C., Ria, L., Poizat, G., Saury, J., \& Durand, M. (2007). Performance induced emotions experienced during high-stakes table tennis matches. Psychology of Sport and Exercise, 8(1), 25-46. https://doi.org/10.1016/j.psychsport.2006.01.004

Sève, C., Saury, J., Theureau, J., \& Durand, M. (2002). Activity organization and knowledge construction during competitive interaction in table tennis. Cognitive Systems Research, 3(3), 501-522. https://doi.org/10.1016/S1389-0417(02)00054-2

Simondon, G. (1989) Du mode d'existence des objets techniques. Paris: Aubier.

Suchman, L. (1993). Response to Vera \& Simon's situated action: a symbolic interpretation. Cognitive Science, 17(1), 71-75. https://doi.org/10.1016/S0364-0213(05)80011-4

Teiger, C., Barbaroux, L., David, M., Duraffourg, J., Galisson, M.-T., Laville, A., \& Thareaut, L. (2006). Quand les ergonomes sont sortis du laboratoire... à propos du travail des femmes dans l'industrie électronique (1963-1973). Perspectives interdisciplinaires sur le travail et la santé, 8(2). https://doi.org/10.4000/pistes.3045

Teiger, C., \& Lacomblez, M. (Eds.). (2013). (Se) Former pour transformer le travail. Laval : PUL.

Theureau, J. (1992). Le cours d'action: Analyse sémiologique - Essai d'une anthropologie cognitive située. Berne : Peter Lang.

Theureau, J. (1997a). L'émergence d'un complexe d'échanges à travers les trajets des voyageurs : essai méthodologique. In D. Bayart, A. Borzeix, M. Lacoste, \& J. Theureau (Eds.), Les traversées de la gare : la méthode des trajets pour analyser l'information-voyageurs (pp. 145-190). Paris : DRAST.

Theureau, J. (1997b). L'utilisation des simulateurs de salle de contrôle de réacteur nucléaire et de cockpit d'avion à des fins autres que de formation : présentation et discussion des tendances 
actuelles. In P. Béguin \& A. Weill-Fassina (Eds.), La simulation en ergonomie : connaître, agir, et interagir (pp. 113-136). Toulouse : Octarès.

Theureau, J. (2000) Activité, représentation de l'activité et... gestion. In P. Lorino (Ed.), Enquêtes de gestion, à la recherche du signe dans l'entreprise (pp. 295-325). Paris: L'Harmattan.

Theureau, J. (2003). Course-of-action analysis and course-of-action centered design. In E. Hollnagel (Ed.), Handbook of cognitive task design (pp. 55-81). Mahwah : Lawrence Erlbaum.

Theureau, J. (2004). Le cours d'action: Méthode élémentaire. Toulouse : Octarès.

Theureau, J. (2006). Le cours d'action: Méthode développée. Toulouse : Octarès.

Theureau, J. (2009). Le cours d'action: Méthode réfléchie. Toulouse : Octarès.

Theureau, J. (2010). Les entretiens d'autoconfrontation et de remise en situation par les traces matérielles et le programme de recherche " cours d'action ». Revue d'anthropologie des connaissances, 4(2), 287-322. https://doi.org/10.3917/rac.010.0287

Theureau, J. (2012). Antropología cognitiva y antropotecnología. Laboreal, 8(2). https://doi.org/ 10.4000/laboreal.6606

Theureau, J. (2015a). Le cours d'action : L'énaction \& l'expérience. Toulouse : Octarès.

Theureau, J. (2015b). 0 curso da açao método elementar. Belo Horizonte : Fabrefactum.

Theureau, J. (2019). Le cours d'action : Économie \& Activités - Suivi de Note sur l'éthique. Toulouse: Octarès.

Theureau, J., \& Filippi, G. (2000). Analysing cooperative work in an urban traffic control room for the design of a coordination support system. In P. Luff, J. Hindmarsh \& C. Heath (Eds.), Workplace studies (pp. 68-91). Cambridge: Cambridge University Press.

Theureau, J., Filippi, G., Saliou, G., \& Vermersch, P. (2001, September). Development of a methodology for analysing the dynamic collective organisation of the reactor operator's and supervisor's courses of experience while controlling a nuclear reactor in accidental situations in full scope simulated control rooms. Communication presented at the $8^{\text {th }}$ European Conference on Cognitive Science Approaches to Process Control, Munich, Germany.

Theureau, J., \& Jeffroy, F. (Eds.). (1994). Ergonomie des situations informatisées : La conception centrée sur le cours d'action des utilisateurs. Toulouse : Octarès.

Theureau, J., \& Pinsky, L. (1983). Action et parole dans le travail infirmier. Psychologie Française, $28(3-4), 255-264$.

Theureau, J., \& Pinsky, L. (1984). Paradoxes de l'ergonomie de conception et logiciel informatique. Revue des conditions de travail, 9.

Tort B. (1974). Bilan de l'apport de la recherche scientifique à l'amélioration des conditions de travail. Rapport du Laboratoire de Physiologie du travail et d'Ergonomie 47, Paris : CNAM.

Vera, A., \& Simon, H. (1993). Situated action : A symbolic interpretation. Cognitive Sciences, 17(1), 7-48. https://doi.org/10.1207/s15516709cog1701_2

Veyrunes, P., \& San Martin, J. (2016). Analizar las interacciones en el aula durante el recitation script : ¿Qué implicaciones para la formación de los profesores? In J. Manzi \& M.R. García (Eds.), Abriendo las puertas del aula : transformación de las prácticas docentes (pp. 93-124). Santiago :

Ediciones UC.

Viau-Guay A. (2009). Analyse de l'activité déployée lors de difficultés professionnelles - Contribution à la formation initiale des ergonomes, Thèse de doctorat, Université Laval, Québec. 
Vion, M. (1993). Analyse de l'apprentissage médié « sur le tas » : Le cas du travail de guichet à l'hôpital, Thèse de doctorat, Université de Paris 13, Paris.

Vors, O., \& Gal-Petitfaux, N. (2008). Mettre une classe au travail en Réseau Ambition Réussite : des formes typiques d'interaction enseignant-élèves lors de leçons d'EPS. Travail et formation en éducation, 2. Récupéré sur http://journals.openedition.org/tfe/724

Winograd, T., \& Flores, F. (1986). Understanding computers and cognition: A new foundation for design. Norwood: Ablex.

Wisner, A. (1995). Situated cognition and action: implication for ergonomics work analysis and anthropotechnology. Ergonomics, 38(8), 1542-1583. https://doi.org/10.1080/00140139508925209

\section{NOTES}

1. The notion of a research program takes on a particular meaning here and will be explained further on (Lakatos, 1994).

2. Today and in retrospect, we would prefer the notion of "the course of activity." However, it is difficult to change a key term that has come to be identified with a research program and the researchers involved in it.

3. Taking the "workers' voice" seriously also aligned this research with certain activist and political engagements of the time. The work carried out in Italy during this period reinforced the importance of the "workers' voice," making it possible to establish certain methods to access it and thus opening on to various attempts to develop the active participation of operators in ergonomic analysis.

4. In a context where academic recognition of ergonomics was a pressing issue, breaking free from these disciplines was a daring move. It is probably this same context that led Wisner to propose a strong demarcation between ergonomics and anthropotechnology (Geslin, 2012; Theureau, 2012). The intent was to confine the academic risks (Daniellou, 2006, p. 8) and not expose ergonomics to criticisms and charges related to its unscientific being (already clearly identified in its relations to psychology and physiology). This initial demarcation between anthropotechnology and ergonomics would benefit from being reexamined today because of the advances in course-of-action research and the heritage and openings toward a "renewed" anthropotechnology that might be implemented within the framework of the course-of-action program.

5. This cognitive anthropology, however full of promise, has fallen somewhat into disuse today, despite its undeniable contributions on the role of culture (including material) in cognition and the situated character of cognition (which cannot be dissociated from the spatial, material, social, and cultural environment).

6. Wisner very early on underlined the preponderant place accorded to anthropology in the anthropotechnological project. Wisner's primary references were to be found in classical and French cultural anthropology (marked by the work and presence of Lévi-Strauss, and not those of Malinowski as in cognitive anthropology). As Geslin (2006) pointed out, his first attempts at rapprochement with French anthropologists ended in failure, and it was not until the end of the 1980s that this collaborative project saw the light of day, no doubt because of the evolution of anthropology in its relations with transformative or design aims.

7. The first wave of systematization-dissemination, the elementary method, involved both the empirical course-of-action program and the associated technological program of "situation engineering" (Theureau, 1992; Theureau \& Jeffroy, 1994) - labeled as such to distinguish itself from the usual "artifact engineering." Theureau's work (2004) then returned mainly to the 
empirical course-of-action program, with some revisions to the elementary method. The second wave of systematization, the developed method, was presented by Theureau (2006) and was essentially a progress report on the development of concepts and methods between 1994 and 2005 (see also Theureau, 2003). It updated the concepts and methods proposed in the first systematization-dissemination, while providing an analytical framework that was more coherent, systematic and fruitful from an empirical point of view. This last wave of systematization-dissemination was extended by two other works that further specified certain notions (while trying to place them in a wider notional universe), outlined a philosophical research program, and opened perspectives for future research (Theureau, 2009, 2015a). To be complete, let us here note the publication of a revised version of a book on the elementary method in Portuguese (Theureau, 2015b) and a book on economics and based on the theoretical speculations and lessons learned from the course-of-action methods for the empirical analysis of human activity (Theureau, 2019).

8. According to Simondon (1989), the notion of concretization makes it possible to differentiate the individuation of technical objects from that of individuals. The technical object, as opposed to the natural object that is concrete from its genesis, tends toward concretization - that is, toward an entirely unified coherence. From this point of view, we can say that over time the course-of-action program has become increasingly more "coherent with itself," with a global conceptual overdetermination of all its components and their increasingly strong integration.

9. And this despite the absence of academic and institutional links. A. Wisner and M. de Montmollin were decisive links to the university for the course-of-action program. Both were ultimately very supportive, indirectly and directly, of course-of-action research in its early stages, even though there were many heated debates with Wisner. These academic links (whether in terms of research or the initial training of ergonomists) gradually weakened.

10. Comparable initiatives would be useful within the enaction paradigm in order to specify the relationships that the empirical course-of-action program has maintained, still maintains or is likely to maintain with the programs that in part support it or are inspired by it in the neurosciences and cognitive sciences.

11. The workbench includes (1) all the material and conceptual tools for analysis, interpretation, modeling and refutation (generic analytical model, modeling methods, simulation tools), and (2) all the methods for the participation of actors in the analysis of their activity and the design of transformations in their situations or the future situations of other actors.

12. This article presents a general description of theoretical objects. For more information, see Theureau $(2006 ; 2009)$.

13. For early essays on self-confrontation, see Pinsky, 1992; Pinsky \& Theureau, 1982, 1987; for the latest synthesis on self-confrontation and reenactment interviews, see Theureau, 2010.

14. Ricœur's expression, taken up by Theureau (2006).

\section{ABSTRACTS}

The "course of action" empirical and technological research program was developed in the field of ergonomics during the 1980s and 1990s. It was then extended to other fields of research and action beyond the boundaries of ergonomics. This contribution proposes an archeology of knowledge with the aim of gaining an understanding not only of the "course of action" research program (and its concreteness), but also of the notions/concepts/methods/models that it 
proposes for both analysis and design. By rapidly scanning both the history and the conceptual universe of the "course of action" research program, this article aims (1) to point out the main empirical and technological contributions of this program and the potential it still holds (for work/activity analysis and for design), and (2) to help to make sense of certain concepts and analytical notions by mentioning the context of their emergence and evolutions.

Le programme de recherche empirique et technologique "cours d'action » est apparu dans le champ de l'ergonomie au cours des années 80-90. Il a ensuite progressivement fait l'objet d'une extension à d'autres domaines de recherche et d'intervention avec des recherches débordant les frontières de l'ergonomie. Cette contribution présente une archéologie des connaissances visant à faire comprendre le programme de recherche " cours d'action » (et sa concrétude), mais aussi les démarches/modèles d'analyse du travail, de l'activité et de conception qu'il propose. En balayant à la fois l'historique et l'univers conceptuel du programme « cours d'action », cet article vise 1) à pointer les principaux apports de ce programme et le potentiel qu'il recèle encore en termes d'analyse du travail/de l'activité et pour la conception, et 2) à aider à la compréhension de certains concepts et de certaines notions analytiques en mentionnant notamment le contexte de leur émergence et les motifs de certaines évolutions.

\section{INDEX}

Mots-clés: cours d'action, observatoire, cadre sémiologique, programme de recherche empirique, programme de recherche technologique, analyse de l'activité

Keywords: course of action, semiological framework, empirical research program, technological research program, activity analysis

\section{AUTHORS}

\section{GERMAIN POIZAT}

University of Geneva, Switzerland - germain.poizat@unige.ch

\section{JULIA SAN MARTIN}

University of Aysén, Chile - julia.sanmartin@uaysen.cl 